\title{
Spectrum Sharing in Cognitive Radio Work Using Goodput Mathematical Model for Perfect Sensing, Zero Interference and Imperfect Sensing, Non Zero Interference
}

\author{
Ojo Festus Kehinde ${ }^{1}$, Fagbola Felix Adetunji ${ }^{2}$ \\ ${ }^{1}$ Department of Electronic and Electrical Engineering, Ladoke Akintola University of Technology, Ogbomoso, Nigeria \\ ${ }^{2}$ Department of Works \& Physical Planning, University of Lagos, Yaba, Lagos, Nigeria
}

Email address:

fkojo@lautech.edu.ng (F. K. Ojo), ffagbola@unilag.edu.ng (F. A. Fagbola)

\section{To cite this article:}

Ojo Festus Kehinde, Fagbola Felix Adetunji. Spectrum Sharing in Cognitive Radio Work Using Goodput Mathematical Model for Perfect Sensing, Zero Interference and Imperfect Sensing, Non Zero Interference. International Journal of Wireless Communications and Mobile Computing. Vol. 3, No. 6, 2015, pp. 58-65. doi: 10.11648/j.wcmc.20150306.11

\begin{abstract}
In recent years, there has been increase in the demand for spectrum allocation as wireless communication witness rapid growth on a daily basis. Literatures have established that this spectrum is scarce and more than $70 \%$ of the available spectrum is not utilized optimally. This paper proposes a model called Goodput model by which the under-utilized spectrum can be shared effectively between primary users and the secondary users without causing harmful interference between the users and also find solution to the problem of increasing demand for spectrum allocation on an already scarce spectrum. Goodput is a mathematical modeling in which the total amount of primary and secondary data that is successfully delivered per unit time can be used as performance index. Compared to other models, the Goodput model with zero interference, perfect sensing and imperfect Sensing, non-zero interference is used to determine the secondary users that will be able to use unoccupied portion of radio frequency channel of primary users with different values of data probability of arrival. Result shows that, the point of intersection between $n p$ and $N(1-p)$ is the optimum point of interference, where $n, N$, and $p$ are number of secondary users, number of primary users, and Probability of data arrival rate respectively. Below the optimum point of interference (left side of the point), all the secondary users will transmit opportunistically without interference. However, above the optimum point of interference (right side of the point), there will be interference between any secondary users that attempt to transmit.
\end{abstract}

Keywords: Cognitive Radio, Spectrum Sharing, Primary User, Secondary User, Goodput

\section{Introduction}

Radio frequency spectrum can be defined as the entire spectrum of electromagnetic frequencies used for communication and broadcasting of radio, radar and television. Radio frequency (RF) is the rate of oscillation around $3 \mathrm{kHz}$ to $3,000 \mathrm{GHz}$ which corresponds to the frequency of radio waves and the alternating current which carry radio signals (Wikipedia, 2014). Cognitive radio is thereby a better technique to fulfill the utilization of radio frequency spectrum as most communication systems go wireless. Both licensed and unlicensed users can use the frequency spectrum using cognitive radio technique. License users are the primary users while the unlicensed users are the secondary users. Primary users allocate the spectrum to the secondary users on demand without degrading its own performance using spectrum sharing techniques, (Varaka, et al. 2013). Distribution of the spectrum among the secondary users according to the usage cost is called Spectrum sharing, (Varaka, et al. 2013). It is the simultaneous usage of a specific radio frequency band in a specific geographical area by a number of independent users. Also, spectrum sharing in cognitive radio network allows cognitive users to share the spectrum bands of the licensedband users. However, the cognitive radio users have to restrict their transmitting power so that the interference caused to the licensed-band users is kept below a certain threshold, (Haykin, 2005). International body such as International Telecommunication Union (ITU) harmonize usage of radio frequency spectrum allocation, while national bodies such as Nigerian Communication Commission (NCC) and Nigerian Broadcasting Commission (NBC) assign the bands and license to service providers such as GSM service providers, Radio \& 
Television stations, internet service providers (ISP) etc. Interestingly, a portion of radio frequency spectrum is dedicated to industrial scientific \& medical (ISM) bands which are unlicensed, protective and non-interference. Therefore, the issue of Spectrum sharing cannot be over emphasized in today wireless communication; in fact it brings improvement in spectrum congestion, provision of additional bandwidth capacity, improvement in quality of service, and provision of emergency network when the existing one is not operational due to destruction of infrastructures; hence a need for proper consideration of sharing techniques.

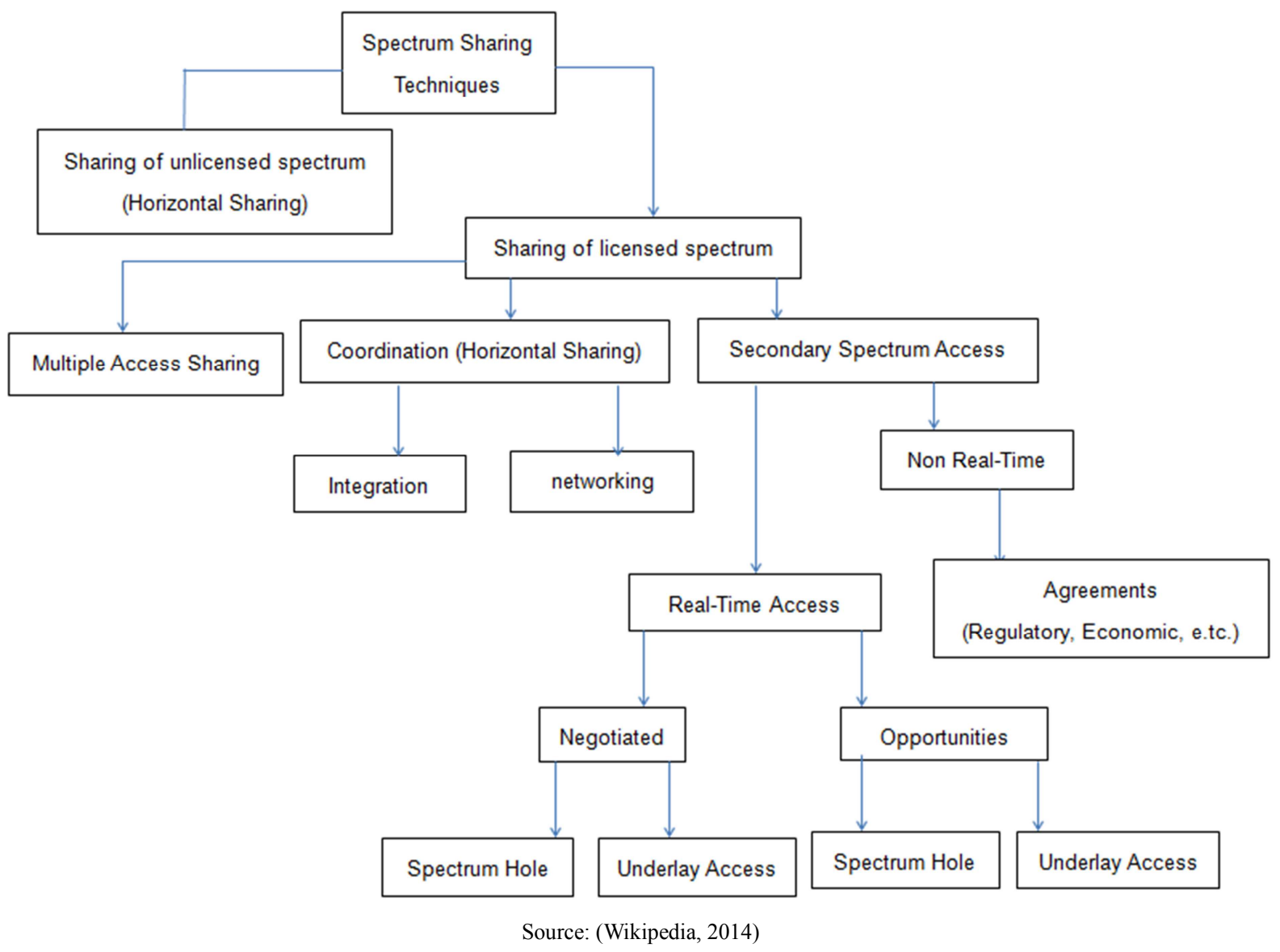

Figure 1. Classification of Unlicensed Spectrum Sharing.
A game theoretical model to analyze dynamic spectrum sharing was presented by Jiandet al, (2007). Game theoretical dynamic spectrum sharing has been extensively studied for more flexible, efficient and fair spectrum usage through analyzing the intelligent behaviors of network user equipped with cognitive radio devices. The authors described the game models for dynamic spectrum sharing for various networking scenarios such as belief assisted pricing and auction based spectrum sharing game. Distributed Spectrum Allocation via local bargaining proposed a local bargaining approach to achieve distributed conflict free spectrum assignment adapted to network topology charges, (Cao et al, 2005).

Also a study of repeated Spectrum Sharing Game Model was carried out by (Etkin, 2005) where the spectrum sharing problem among multiple secondary users for interference

\section{Related Works on Spectrum Sharing}

According to Wigglinski, (2009), there are three physical dimensions to share the spectrum; these are time (S), frequency $(\mathrm{Hz})$ and space $\left(\mathrm{m}^{2}\right)$. Also, there are several ways of classifying spectrum sharing. Licensed spectrum sharing which is sub divided into Horizontal and Vertical. Unlicensed spectrum sharing which is sub divided into horizontal and single system. The classifications are shown in Figure 1. constrained wireless systems in a non - cooperative game frame work. Their study is focused on investigating self enforcing spectrum sharing game rules and the corresponding game efficiently measured in total throughput obtained from available spectrum resources. (IEEE DySPAN, 2005).

\section{The System Model}

The system model adopted in this work is presented in Figure 2. $P u$ are the primary users, $S u$ are the secondary users and the circles around the secondary nodes are sensing regions where primary users are perfectly detected while the colored circles are different sub channels. The dotted lines are corresponding primary/secondary users that do not have data to transmit (OFF). 


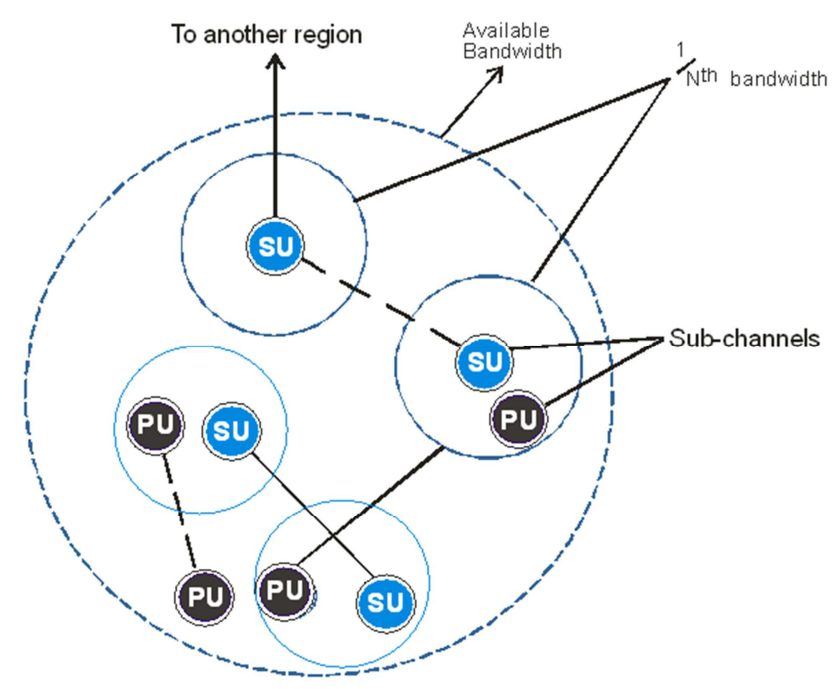

Figure 2. The system model.

For perfect sensing, certain resources are considered which is equally shared among $N$ primary users (primary transmitter- receiver pairs). Each primary radio is licensed to transmit on a channel that spans $\left(1 /{ }_{N}\right)$ th of the available bandwidth. Assuming the data traffic arrives at each primary user with a probability of arrival $P$. The channel is also to be used opportunistically by $n$ secondary users in order to allow higher spectral efficiencies. Assuming that delay intolerant data arrives at the secondary users with the same arrival probability $P$, and the transmission at the primary and secondary users take place at the rate $R$, the primary users can reliably transmit their data at rate $R$. Then the secondary users may be considered lost if there is no free channel for secondary transmission; or more secondary users select the same unoccupied licensed channel.

\section{Modeling of Perfect Sensing and Zero Interference}

The sum Goodput of the primary users is (assuming no collision between primary users)

$$
G_{p}^{s u m}=\mathrm{R} \times \mathrm{N} \times \mathrm{P}
$$

While the sum Goodput of the secondary users depends on the number of unoccupied sub channels and could be written as:

$$
G_{s}^{\text {sum }}=\sum_{i=1}^{N}\left(\begin{array}{c}
N \\
i
\end{array}\right) p^{N-i}(1-P)^{\mathrm{i}} G_{s}^{\text {sum }}(\mathrm{i})
$$

Where $G_{S}^{\text {sum }}(\mathrm{i})$ is the secondary goodput given that $i$ of the $\mathrm{N}$ primary users do not have data to transmit (OFF).

If we condition on the number of secondary users who have data to transmit $(\mathrm{ON})$ we could express $G_{s}^{\text {sum }}(\mathrm{i})$ as

$$
G_{s}^{\text {sum }}(\mathrm{i})=\sum_{j=1}^{n}\left(\begin{array}{c}
n \\
j
\end{array}\right) p^{j}(1-P)^{\mathrm{n}-\mathrm{j}} G_{s}^{\text {sum }}(\mathrm{i}, \mathrm{j})
$$

Where $G_{s}^{\text {sum }}$ is the secondary goodput, given that $\mathrm{i}$ subchannels are unoccupied and $\mathrm{j}$ secondary users are ON

$$
G_{s}^{s u m}(\mathrm{i}, \mathrm{j})=\mathrm{R}\left(1-\frac{1}{i}\right)^{j-i}
$$

If we substitute equation (4) into equation (3), we have

$$
G_{s}^{\text {sum }}(\mathrm{i})=\sum_{j=1}^{n}\left(\begin{array}{l}
n \\
j
\end{array}\right) p^{j}(1-P)^{\mathrm{n}-\mathrm{j}} \mathrm{R}\left(1-\frac{1}{i}\right)^{j-1}
$$

The sum goodput is the addition of equations (1) and (5)

$$
G_{s}^{\text {sum }}=\operatorname{RNP}\left[1+\frac{n}{N} \sum_{i=1}^{N}\left(\begin{array}{c}
N \\
i
\end{array}\right) p^{N-i}(1-P)^{\mathrm{i}}\left(1-\frac{\mathrm{P}}{\mathrm{i}}\right)^{\mathrm{n}-\mathrm{i}}\right](6)
$$

At the optimum, $\frac{d G}{d n}=0$, then,

$$
n P=N(1-P)
$$

Therefore when $n P>N(1-P)$ there will be no interference. This is a case of perfect sensing, zero interference scenario.

\section{Modeling of Imperfect Sensing and Non Zero Interference}

In order to model and determine the effect of sensing and interference tolerance on the goodput maximum number of secondary users, it is required to determine the steady state probabilities of the detected state (i.e. including sensing errors).

The steady state probability observed without the true knowledge of primary user activity and therefore, sensible to sensing errors are:

$$
\mathrm{P}_{(\mathrm{ij})}^{\mathrm{S}}=\sum_{\mathrm{n}=0}^{\mathrm{N}_{\mathrm{C}}} \mathrm{b}(\mathrm{i}, \mathrm{n}) \mathrm{P}_{(\mathrm{nj})}
$$

Average number of primary users and secondary users (i.e. average served traffic) is computed as:

$$
\begin{aligned}
& \mathrm{N}_{\mathrm{P}}=\sum_{5_{\mathrm{ij}}} \mathrm{i} \cdot \mathrm{P}_{\mathrm{ij}} \\
& \mathrm{N}_{\mathrm{S}}=\sum_{5_{\mathrm{ij}}} \mathrm{j} \cdot \mathrm{P}_{\mathrm{ij}}
\end{aligned}
$$

Average number of sensed primary users

$$
\mathrm{N}_{\mathrm{p}}^{\mathrm{i}}=\sum_{5_{\mathrm{ij}}} \mathrm{i} \cdot \mathrm{P}_{\mathrm{ij}}^{\mathrm{S}}=\sum_{\mathrm{S}_{\mathrm{ij}}} \mathrm{i}\left[\sum_{\mathrm{n}=0}^{\mathrm{N}_{\mathrm{i}}} \operatorname{bin} \cdot \mathrm{P}_{(\mathrm{nj})}\right]
$$

The blocking probability for secondary users can be computed as:

$$
\mathrm{P}_{\mathrm{B}}^{\mathrm{SU}}=\sum_{\mathrm{i}=0}^{\mathrm{N}_{\mathrm{C}}} \sum_{\mathrm{j}=\mathrm{N}_{\mathrm{C}}-\mathrm{i}}^{\mathrm{N}} \mathrm{P}_{(\mathrm{ij})}^{\mathrm{S}}=\sum_{\mathrm{i}=0}^{\mathrm{N}_{\mathrm{C}}} \sum_{\mathrm{j}=\mathrm{N}_{\mathrm{C}}-\mathrm{i}}^{\mathrm{N}_{\mathrm{C}}}\left[\sum_{\mathrm{n}=0}^{\mathrm{N}}\left(\mathrm{b}_{\mathrm{in}}\right) \mathrm{P}_{\mathrm{nj}}\right]
$$

Interruption probability can be computed as: 


$$
\mathrm{P}_{\mathrm{INT} .}=1-\frac{\mathrm{T}_{\mathrm{S}}^{\text {served }}}{\mathrm{T}_{\mathrm{S}}\left(1-\mathrm{P}_{\mathrm{B}}^{\mathrm{SU}}\right)}=1-\frac{\mathrm{N}_{\mathrm{S}}}{\frac{\lambda_{\mathrm{S}}}{\mu_{\mathrm{S}}}\left(1-\mathrm{P}_{\mathrm{B}}^{\mathrm{S}}\right)}
$$

$$
\text { Where } \mathrm{P}_{\mathrm{S}}^{\text {served }}=\mathrm{T}_{\mathrm{S}}\left(1-\mathrm{P}_{\mathrm{B}}^{\mathrm{SU}}\right)\left(1-\mathrm{P}_{\mathrm{INT} .}\right)
$$

$\mathrm{P}_{\mathrm{S}}^{\text {served }}$ is the average number of secondary users.

Also, given a maximum possible number of collisions to be $\mathrm{C}$, the collision probability ratio (interference probability) in the state $S_{i j}$ as

$$
\mathrm{P}_{\mathrm{C}(\mathrm{ij})}=\frac{\mathrm{N}_{\mathrm{C}}^{\text {upper band }}(\mathrm{ij})}{\mathrm{C}}
$$

Error sensing interruption probability can be computed as:

$$
\mathrm{P}_{\mathrm{INT} .}=1-\frac{\mathrm{T}_{\mathrm{S}}^{\text {served }}}{\mathrm{T}_{\mathrm{s}}\left(1-\mathrm{P}_{\mathrm{B}}^{\mathrm{sa}}\right)}=1-\frac{\mathrm{N}_{\mathrm{S}}}{\frac{\lambda_{\mathrm{s}}}{\mu_{\mathrm{s}}}\left(1-\mathrm{P}_{\mathrm{B}}^{\mathrm{S}}\right)}
$$

Where

$$
\mathrm{T}_{\mathrm{S}}^{\mathrm{served}}=\mathrm{T}_{\mathrm{S}}\left(1-\mathrm{P}_{\mathrm{B}}^{\mathrm{SU}}\right)\left(1-\mathrm{P}_{\mathrm{INT} .}\right)
$$

$\mathrm{T}_{\mathrm{S}}^{\text {served }}$ is the average number of secondary users.

Also, given a maximum possible number of collision to be $\mathrm{C}$, the collision probability ratio (interference probability) in

$$
\begin{gathered}
\frac{\mathrm{dG}_{\mathrm{IM}}^{\mathrm{SUM}}}{\mathrm{dn}}=\mathrm{P}_{\mathrm{IM}} \mathrm{C}^{\prime}\left[\frac{1}{\mathrm{~N}} \sum_{\mathrm{i}=1}^{\mathrm{N}}\left(\begin{array}{l}
\mathrm{N} \\
\mathrm{i}
\end{array}\right) \mathrm{P}_{\mathrm{IM}}^{\mathrm{N}-\mathrm{i}}\left(1-\mathrm{P}_{\mathrm{IM}}\right)^{\mathrm{i}}\left(1-\frac{\mathrm{P}_{\mathrm{IM}}}{\mathrm{i}}\right)^{\mathrm{n}-1}+\frac{\mathrm{n}}{\mathrm{N}} \operatorname{In}\left(1-\frac{\mathrm{P}_{\mathrm{IM}}}{\mathrm{i}}\right) \sum_{\mathrm{i}=1}^{\mathrm{N}}\left(\begin{array}{l}
\mathrm{N} \\
\mathrm{i}
\end{array}\right) \mathrm{P}_{\mathrm{IM}}^{\mathrm{N}-\mathrm{i}}\left(1-\mathrm{P}_{\mathrm{IM}}\right)^{\mathrm{i}}\left(1-\frac{\mathrm{P}_{\mathrm{IM}}}{\mathrm{i}}\right)^{\mathrm{n}-1}\right] \\
\frac{\mathrm{dG}_{\mathrm{IM}}^{\text {SUM }}}{\mathrm{dc}}=\frac{\mathrm{P}_{\mathrm{iM}} \mathrm{C}^{\prime}}{\mathrm{N}} \sum_{\mathrm{i}=1}^{\mathrm{N}}\left(\begin{array}{l}
\mathrm{N} \\
\mathrm{i}
\end{array}\right) \mathrm{P}_{\mathrm{IM}}^{\mathrm{N}-\mathrm{i}}\left(1-\mathrm{P}_{\mathrm{iM}}\right)^{\mathrm{i}}\left(1-\frac{\mathrm{P}_{\mathrm{iM}}}{\mathrm{i}}\right)^{\mathrm{n}-1}\left[1+\mathrm{nIn}\left(1-\frac{\mathrm{P}_{\mathrm{iM}}}{\mathrm{i}}\right)\right]=0
\end{gathered}
$$

Since

$$
\begin{gathered}
\frac{\mathrm{P}_{\mathrm{iM}} \mathrm{C}^{\prime}}{\mathrm{N}} \sum_{\mathrm{i}=1}^{\mathrm{N}}\left(\begin{array}{l}
\mathrm{N} \\
\mathrm{i}
\end{array}\right) \mathrm{P}_{\mathrm{iM}}^{\mathrm{N}-\mathrm{i}}\left(1-\mathrm{P}_{\mathrm{iM}}\right)^{\mathrm{i}}\left(1-\frac{\mathrm{P}_{\mathrm{iM}}}{\mathrm{i}}\right)^{\mathrm{n}-1} \neq 0 \\
\Rightarrow 1+\mathrm{n} \sum_{\mathrm{i}=1}^{\mathrm{N}} \operatorname{In}\left(1-\frac{\mathrm{P}_{\mathrm{iM}}}{\mathrm{i}}\right)=0 \\
\mathrm{n}=\frac{-1}{\sum_{\mathrm{i}=1}^{\mathrm{N}}\left[\operatorname{In}\left(1-\frac{\mathrm{P}_{\mathrm{iM}}}{\mathrm{i}}\right)\right]}
\end{gathered}
$$

Also, at the optimum, $\frac{d G}{d n}=0$, then,

$$
\mathrm{nP}=\mathrm{N}(1-\mathrm{P})
$$

Therefore when $\mathrm{nP}<\mathrm{N}(1-\mathrm{P})$, there will be interference (29)

The optimum number of secondary user on $\mathrm{N}$ primary users in order to minimize interference, interruption or collision is given as: state $S_{\mathrm{ij}}$ is given as:

$$
P_{C}(i j)=\frac{N_{C(i j)}^{\text {upper based }}}{C}
$$

Average interference probability,

$$
\mathrm{P}_{\mathrm{C}}=\sum \mathrm{P}_{\mathrm{c}(\mathrm{ij})} \mathrm{P}_{(\mathrm{ij})}
$$

Average interference probability and sensible to sensing error $=$

$$
\mathrm{P}_{\mathrm{C}} \times \mathrm{P}_{\mathrm{ij}}=\mathrm{P}_{\mathrm{imp}}
$$

Average interference probability for sensing error $=$

$$
\mathrm{P}_{\mathrm{C}} \times \mathrm{P}_{\mathrm{ij}}=\mathrm{P}_{\mathrm{imp}}
$$

The goodput under the imperfect sensing, non-zero inference tolerance is given as:

$$
\mathrm{G}_{\mathrm{IMP}}^{\mathrm{SUM}}=\mathrm{P}_{\mathrm{N}} \mathrm{C}^{\prime} \mathrm{N}\left[1+\frac{\mathrm{n}}{\mathrm{N}} \sum_{\mathrm{i}=1}^{\mathrm{N}}\left(\begin{array}{l}
\mathrm{N} \\
\mathrm{i}
\end{array}\right) \mathrm{P}_{\mathrm{IM}}^{\mathrm{N}-\mathrm{i}}\left(1-\mathrm{P}_{\mathrm{IM}}\right)^{\mathrm{i}}\left(\frac{\mathrm{P}_{\mathrm{iM}}}{\mathrm{i}}\right)^{\mathrm{n}-1}\right]
$$

In order to optimize this imperfect sensing, non-zero interference tolerance, we use Newton's or Gradient method of optimization. 


\section{Results \& Discussion}

\subsection{For Perfect Sensing \& Zero Interference Simulations}

In this case we made some assumptions; It is assumed that there is no collision between primary users; there are ten (10) primary users with different probability of arrival $P$ then the goodput of the primary users is simulated and presented as shown in Figure 3.

The plot of Normalized Goodput against the fraction numbers of primary licensed users is shown in Figure 3; when the fraction of licensed primary users is 0.1 and the probability of transmission data arrival $P=0.10$, then the normalized goodput is 0.53 . Also, when the fraction of primary licensed users is 0.2 ; and the probability of transmission data arrival $P=0.20$, the normalized goodput is 0.15 . From the result obtained, it can be established that the lower the number of primary licensed users with lower probability of arrival the higher the normalized goodput G. This satisfies equation (6).

Simulation of the numbers of secondary users that can transmit when the numbers of secondary users that has data to transmit varies.

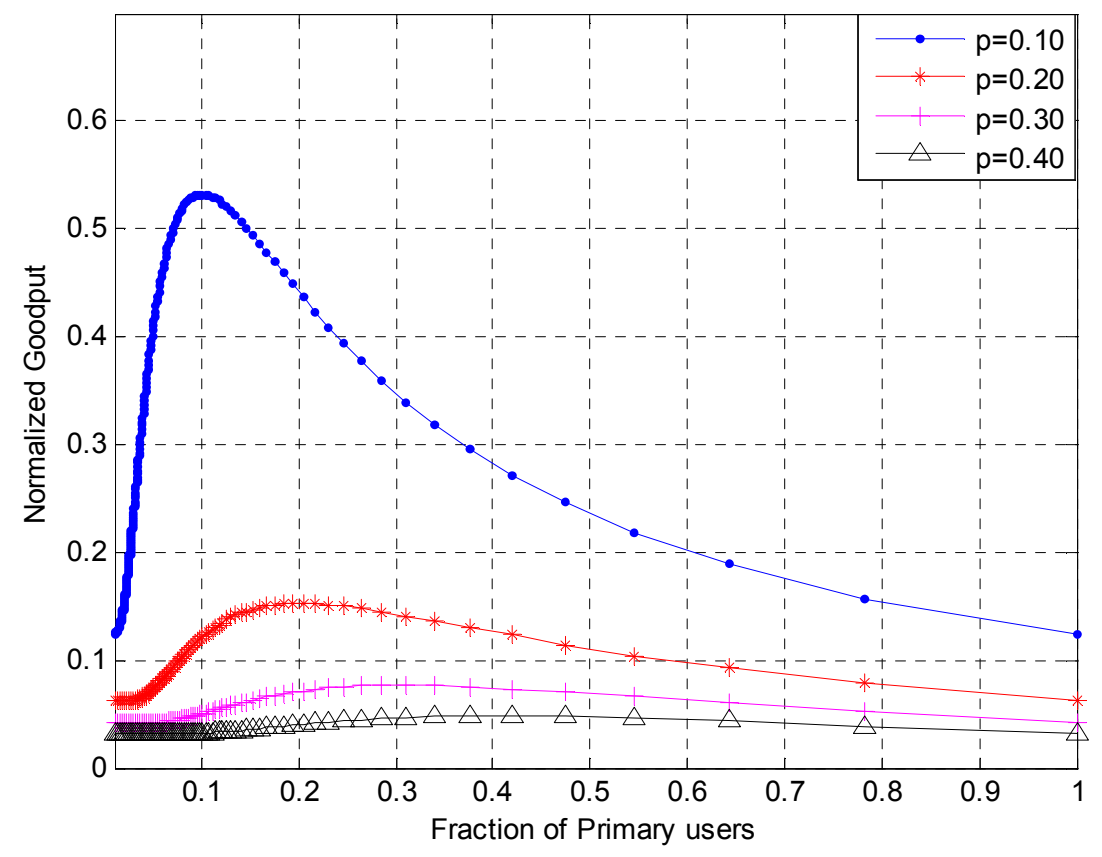

Figure 3. Normalized Goodput against Fraction of Primary users.

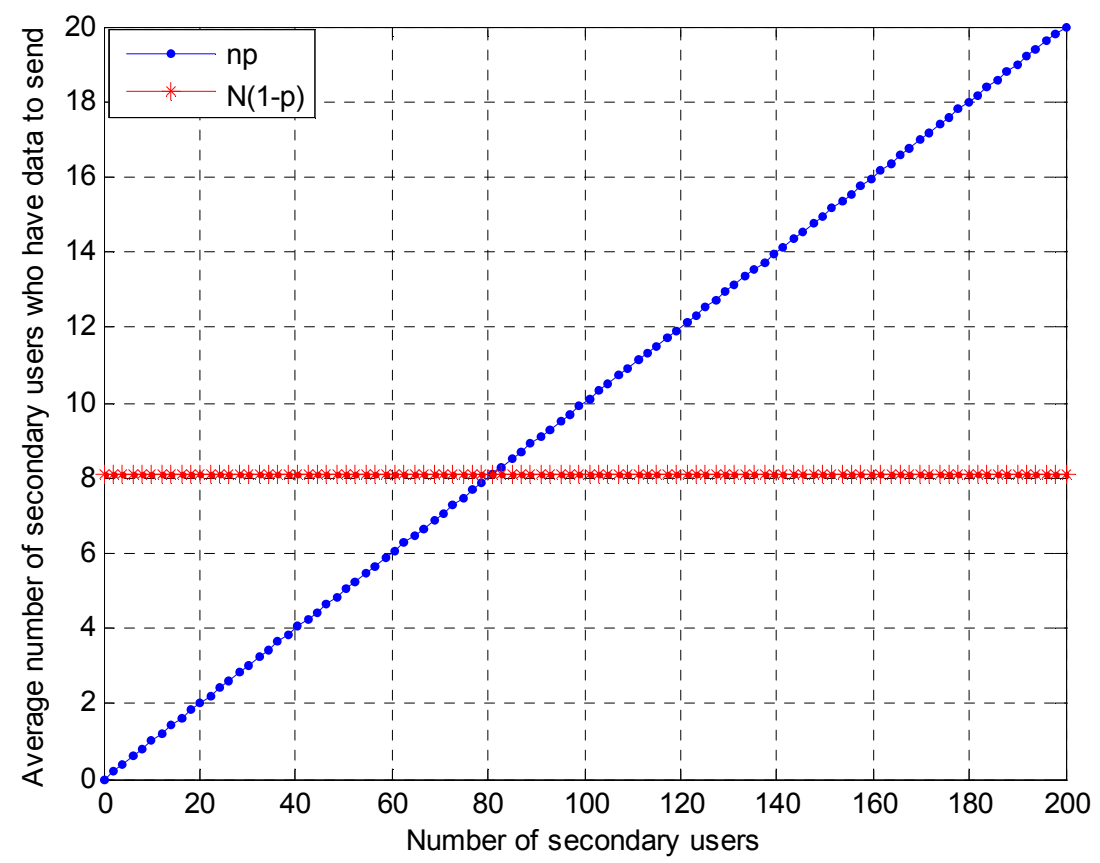

Figure 4. Average number of secondary users who have data to transmit against number of secondary users $(P=0.1)$. 
The number of secondary users that have data to transmit is set at 20 and the total number of secondary users is 200 as shown in Figure 4; then the number of secondary users that can transmit without interference can be determined considering probability of arrival of transmission $P,(P=$ $0.1)$. It is noted that the point of intersection between $n p$ and $N(1-p)$ is the optimum point of interference between the licensed primary users and the opportunistically secondary users. It implies here that, below the optimum point of interference, all the secondary users will transmit opportunistically without interference with the licensed primary users and above the optimum point of interference, there will be interference between any secondary users that transmit and the licensed primary users. It shows that for $P=0.1$, only 8 secondary users out of 20 that have data to transmit will opportunistically transmit without interference since they lie below the optimum point of interference. At $P=0.2$, the simulation result presented in Figure 5 shows that only 7 secondary users out of 40 average numbers of secondary users who have data to send will transmit without interference with the licensed primary users. When the probability of arrival of transmission data increases to $0.3,(P=0.3)$, and the average number of secondary users who have data to transmit increases to 60 as shown in Figure 6 . It is clearly shown that only 6 secondary users out of 60 average numbers of secondary users who have data to send will transmit without interference with the licensed primary users. However, any attempt for the remaining 52 secondary users to transmit will cause harmful effect on the primary users (licensed users).

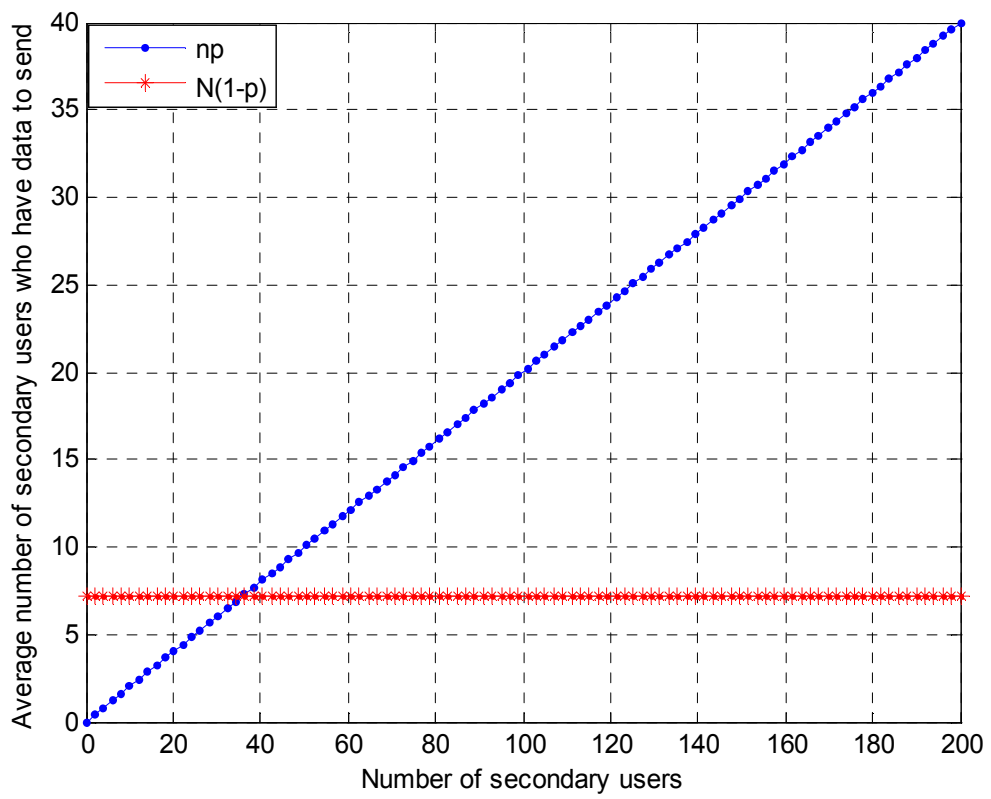

Figure 5. Average number of secondary users who have data to transmit against number of secondary users $(P=0.2)$

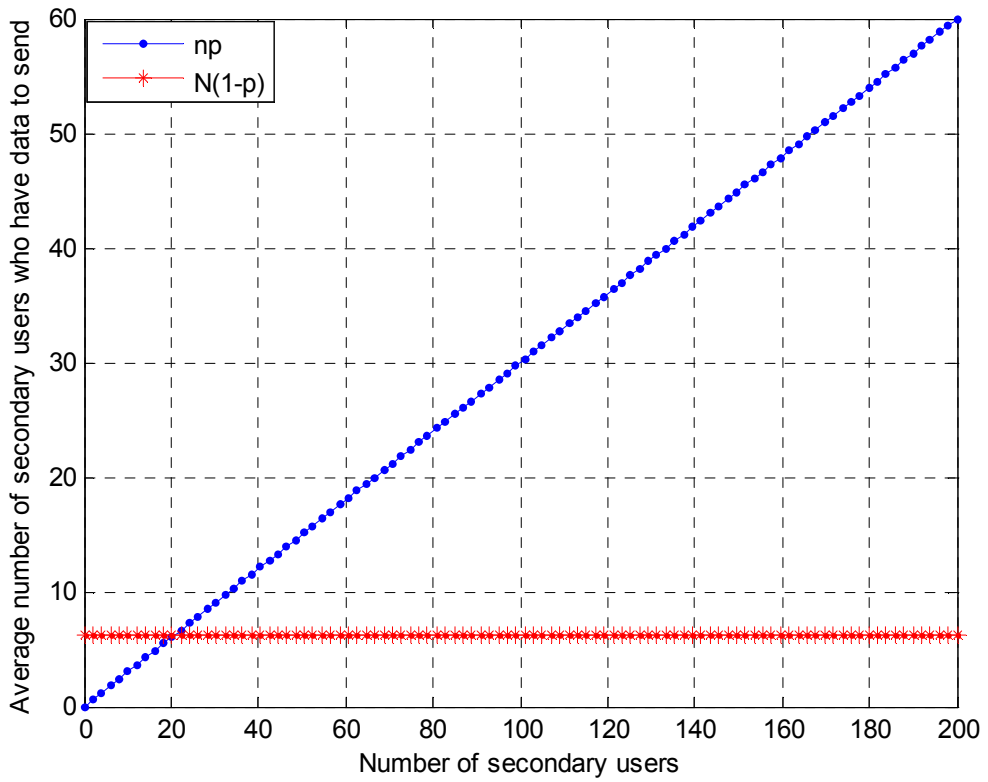

Figure 6. Average number of secondary users who have data to transmit against number of secondary users $(P=0.3)$. 


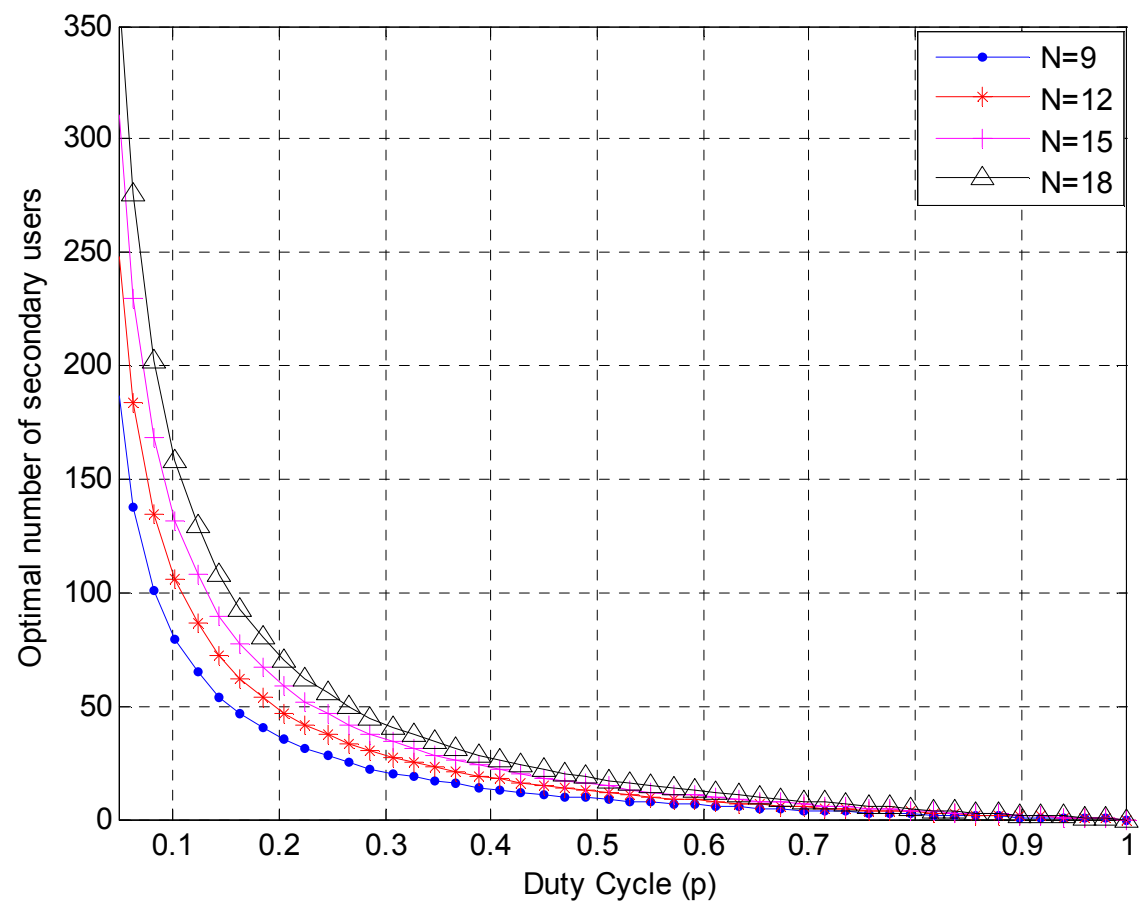

Figure 7. Graph of Optimum Number of Secondary Users against Duty Cycle (p).

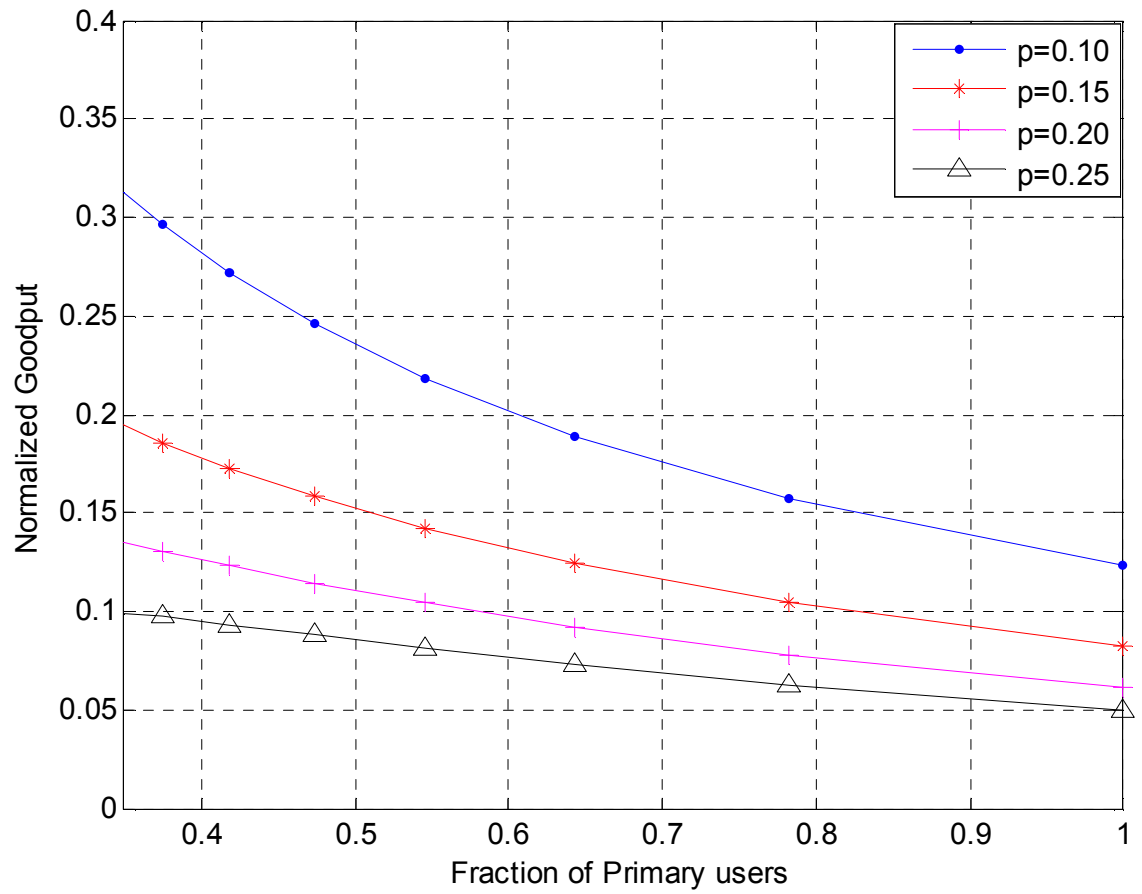

Figure 8. Graph of Normalized Goodput against Fraction of Primary Users.

\subsection{For Imperfect Sensing \& Non Zero Interference Simulations}

Case 1:

With different numbers of $\mathrm{N}$ (number of licensed primary users) and duty cycles, the optimum number of secondary users show that the number of opportunistically secondary users increases when $\mathrm{N}$ increases with a very low value of duty circle as shown in figure 7.

This satisfies equation (27) which shows the number of secondary users that can opportunistically use a specific number of licensed primary users.

Case 2:

In figure 8 , we have different values of Probability of arrival of transmission data $\mathrm{P}$ and fraction of primary users, the goodput of licensed primary users largely depend on the probability of arrival of transmission data $P$.

Normalized goodput has the highest value when $\mathrm{P}=0.1$ and the lowest when $\mathrm{P}=0.25$ with the fraction of licensed primary users of 0.2 and 0.78 respectively. 


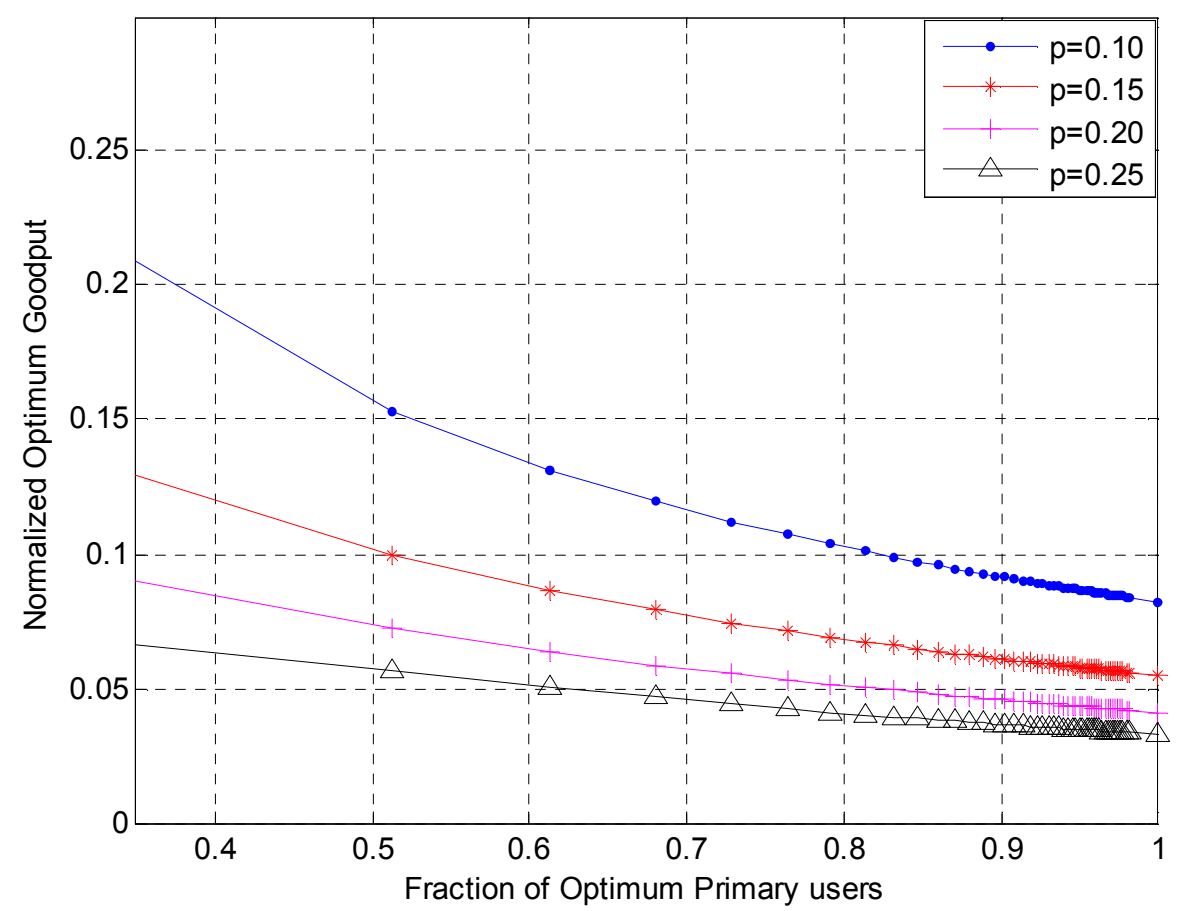

Figure 9. Graph of Normalized Optimum Goodput against Fraction of Optimum Primary Users.

Case 3:

Figure 9 is the normalized goodput plotted against fraction of primary users.

With different values of $\mathrm{P}$, it is observed that the lower the value of $\mathrm{P}$ the higher the goodput. It also follows that the normalized goodput has the highest value when $\mathrm{P}=0.10$, with a few numbers of licensed primary users.

Figure 9 satisfies equation (31).

\section{Conclusion}

The results presented in this paper shows the application of Goodput mathematical model for perfect sensing, zero tolerance and imperfect sensing, non zero tolerance for spectrum sharing in cognitive radio network. It is observed that for high Goodput, perfect sensing and zero interference tolerance, the probability of arrival of signal transmission among the primary and secondary users must be very low in order to have appreciable number of opportunistic secondary users. Also, secondary users are not allowed to transmit above the optimum point of interference between the licensed primary users and the opportunistically secondary users as proposed by Goodput mathematical model.

\section{References}

[1] http://en.wikipedia.org/wiki/ Cognitive_ Radio (Cognitive Radio Communication and Networks: Principles and Practice) retrieved on 24/09/2014 8:18 PM.
[2] http://en.wikipedia.org/wiki/Electromagnetic_Spectrum, retrieved on 8/1/2014 12:02 PM.

[3] A. M. Wigglinski, M. Nekovee, and Y. N T. Hou, (2009), "Cognitive Radio" IEEE VTS, chap.6.

[4] Zhu Jiand and K. J. Ray Liu, (2007), "Cognitive Radio for Dynamic Spectrum Access" IEEE Communications Magazine, pp. 84-94.

[5] L. Cao and H. Zheng, (2005) "Distributed Rule-Regulated Spectrum Sharing" IEEE Journal on Selected Areas of Communications, vol. 20, no.3, pp.150.

[6] R. Etkin, A. Parekh, and D. Tse, (2005) "Spectrum Sharing for Unlicensed bands" Proc. IEEE Dy SPAN, pp.159.

[7] Varaka Uday Kanth, Kolli Ravi Chandra, Rayala Ravi Kumar, (2013) "Spectrum Sharing In Cognitive Radio Networks", IJETT Journal, vol. 4, issue 4,pp.1172.

[8] Haykin, S. (2005) "Cognitive Radio: Brain Empowered Wireless Communications" IEEE Journal on Selected Areas of Communications, vol.23, no.2, pp. 201-220.

[9] Xavier Gelabert, Oriol Sallent, Jordi Pérez-Romero, Ramon Agustí, (2010) "Spectrum sharing in cognitive radio networks with imperfect sensing: A discrete-time Markov model" pp. 2522-2532.

[10] Ana Luz Mendiguchia Gonzalez, Massimiliano Picole and Silvia Colabrese, (2005) "Cognitive Radio: Meaning and Application”, IEEE journal on Cognitive Radio, vol.20, no.4, pp.120.

[11] Sudhir Srinivasa and Syed Ali Jafar, (2008) "Cognitive Radio Networks: How much Spectrum Sharing is Optimal"pp. 1-4. 